6. Preparation of the reagents for use.-a. When the complement is standardised make up a sufficient quantity of the correct dilution to allow 0.5 c.c. for each tube and a little over. $b$. Also make up exactly the same quantity of diluted antigen as shown in the table. Mix in the manner already described for antigen.

\begin{tabular}{|c|c|c|c|c|c|c|c|c|}
\hline No. of tul & & c.c. & & Heart. & & oleste & & Saline \\
\hline 30 & $=$ & 15 & $=$ & 0.6 & + & 0.4 & + & $14 \cdot 0$ \\
\hline 40 & $=$ & 20 & $=$ & 0.8 & + & 0.53 & + & 186 \\
\hline 50 & $=$ & 25 & $=$ & $1 \cdot 0$ & + & 0.67 & + & $23 \cdot 3$ \\
\hline 60 & $=$ & 30 & $=$ & $1 \cdot 2$ & + & 0.8 & + & 28.0 \\
\hline 70 & $=$ & 35 & $=$ & $1 \cdot 4$ & + & 0.93 & + & $32 \cdot 6$ \\
\hline 80 & $=$ & 40 & $=$ & $1 \cdot 6$ & + & 1.06 & + & $37 \cdot 3$ \\
\hline 90 & $=$ & 45 & $=$ & 1.8 & + & $1 \cdot 2$ & + & $42 \cdot 0$ \\
\hline 100 & $=$ & 50 & $=$ & $2 \cdot 0$ & + & $1 \cdot 34$ & + & $46 \cdot 6$ \\
\hline 110 & $=$ & 5 & $=$ & $2 \cdot 2$ & + & $1 \cdot 47$ & + & \\
\hline 120 & $=$ & 60 & $=$ & $2 \cdot \overline{4}$ & + & $1 \cdot 6$ & + & \\
\hline 130 & $=$ & 65 & $=$ & $2 \cdot 6$ & + & 1.73 & + & \\
\hline 140 & $=$ & 70 & $=$ & $2 \cdot 8$ & + & $1 \cdot 86$ & + & 65 \\
\hline 150 & $=$ & 7 & $=$ & 70 & + & . & + & \\
\hline
\end{tabular}

7. The test proper.-Mix the dilated complement and antigen together, and then, without delay, measure 1 c.c. of the mixture into every tube. Shake. Incubate for one hour in the air incubator. Add 0.5 c.c. of the corpuscle-amboceptor mixture to each tube. Place the racks in the waterbath and read results when some are quite laked and others quite opaque-i.e., in about 10 minutes.

8. Reading results. - When judging between complete inhibition and slight hæmolysis, depend more upon opacity than colour. Describe the inhibiting sera as ++++ (complete) $+++;++$ or.+++++ and +++ will be diagnostic of syphilis, ++ and + will be more or less doubtful when the tester has no personal knowledge of the case. If, however, the case is known to have had syphilis, ++ and + assume much more importance. The great majority of cases give ++++ or 0 .

\section{THE OCCASIONAL ABSENCE OF A RISE OF TEMPERATURE FOLLOWING THE ADMINISTRATION OF DIAGNOSTIC DOSES OF TUBERCULIN TO TUBERCULOUS PERSONS.}

By DUNCAN FORBES, M.D., B.Sc. EdIN., D.P.H , IEDICAL OTTICER OF HEALTH OF BRIGHTON; AND

C. W. HUTT, M.A., M.D. OANTAB., D.P.H, SENIOR SCHOOL DOCTOR AND ACTING TUBEROULOSIS OFFTCER, BRIGHTON

IT is well recognised that a local reaction and rise of temperature following the administration of tuberculin does not necessarily indicate the presence of an active lesion, signs of a focal reaction alone giving any evidence likely to be of assistance in the diagnosis. On the other hand, many believe that active disease can definitely be excluded if the usual diagnostic doses of tuberculin are not followed by any marked rise of temperature. Our reason for sending these few notes is to emphasise the fact that patients suffering from active tuberculosis and who have not been previously treated with tuberculin may have no rise of temperature of even $1^{\circ} \mathrm{F}$. above normal following the administration of diagnostic doses of tuberculin. In other words, the absence of a temperature reaction after the administration of maximum diagnostic doses of tuberculin does not prove the absence of active tuberculosis.

CASE 1.-The patient, a male aged 44, had a history of cough on and off for ten years, more marked since November, 1913. In July, 1914, he was admitted to the sanatorium for observation. He had received no tuberculin treatment prior to admission. There was impaired resonance at the right apex, but no sign of active disease. As some doubt existed as to the diagnosis, a short time after admission, at intervals of three and four days, 0.00002 P.T.O. and $\frac{1}{5}, \frac{1}{2}, 1,2$ 5 , and 10 milligrammes of tuberculin (T.) were given. The four-hourly chart showed no rise of temperature, except on the day following the $\frac{1}{2}$ and 1 milligramme doses, when the mouth temperature rose to $98.6^{\circ}$ and $99 \cdot 2^{\circ} \mathbf{F}$.; on two occasions prior to the administration of tuberculin a temperature of $99.2^{\circ}$ had been recorded. The local reaction was slight. The patient's weight steadily rose from $55^{\circ} 5$ kilos on July 17 th to 60 kilos on August 20 th, when he was discharged. A trace of albumin but no tuberole bacilli were found in his sputum at that time.

The patient's condition remained stationary until November, 1915, some 15 months later, when he was readmitted with definite crepitations at the right apex and tubercle bacilli in the sputum. On Dec. 20th, 28th and 31 st, and Jan. 6th $\frac{1}{5}, \frac{1}{2}, 1$, and 5 milligrammes of tuberculin (T.) were administered, followed by no increase of temperature over the normal, except on two occasions, $99^{\circ}$ being recorded on the third day after the $\frac{1}{2}$ and 5 milligramme doses; a temperature of $99^{\circ}$ had been recorded on Dec. 11th a short time prior to the injections. On Jan. 9th there was increase of cough and sputum but no rise in temperature. The sputum was then sent to the Lister Institute for examination in order to exclude the possibility that saprophytic acid-fast organisms had been mistaken for tubercle bacilli the guinea-pigs inoculated showed macroscopic signs of tuberculosis.

This case seems to prove that the routine diagnostic doses of tuberculin may not be followed by a temperature appreciably over the patient's normal temperature $(a)$ at an early stage of the disease when tubercle bacilli cannot be found in the sputum, and $(b)$ at later stages when these are present and even when a focal reaction indicated by increase of cough and sputum is caused.

CASE 2.-The patient, a male aged 2, was admitted suffering from spinal caries and healed tuberculous abscesses on the foot. He received $\frac{1}{2}, \frac{1}{2}$, and 1 milligramme of tuberculin (T.), the highest subsequent temperature being $98 \cdot 6^{\circ} \mathbf{F}$. Five months later an abscess formed on the dorsum of the foot, broke down, and remained open for some time. In this case the maximum dose administered was 1 milligramme, but the child was only 2 years of age.

In this connexion it is interesting to note that of the animals infected with human tubercle bacilli and tested with homologous tuberculin the following gave a temperature reaction $^{1}$ (rises of $0.90 \mathrm{O}$. over the normal): 107 of 124 calves, or 86.3 per cent. ; 6 of 6 goats, or 100 per cent. 10 of 11 pigs, or 90.9 per cent.; and 4 of 4 horses, or 100 per cent. Evidently neither in man nor in animals does the absence of a temperature reaction following tuberculin exclude active tuberculosis.

Brighton.

\section{Shedical Socreties.}

\section{ROYAL SOCIETY OF MEDICINE.}

\section{SECTION OF ELEOTRO-THERAPEUTICS.}

Exhibition of Case and of Skiagrams. - Gas Gangrene.

A MEETING of this section was held on Oct. 20th, Dr. G. Harrison Orton, the President, being in the chair.

Dr. E. P. Cumberbatch showed a female patient, about 60 years of age, for the purpose of illustrating what could be accomplished by the diathermic cautery in cases of malignant disease. In 1913 she came to him with a rodent ulcer on the scalp, measuring 1 by $\frac{3}{4}$ in. in diameter. Zinc ionisation, repeated six times, produced no benefit; neither did a course of $\mathrm{X}$ ray treatment. A combination of both those methods was equally barren of results, for at the end of 10 months the diameter of the ulcer had increased to $1 \frac{3}{4}$ by $1_{\frac{1}{3}}$ in. Accordingly, in March, 1914, he commenced the use of the diathermic cautery, cauterising with it the edges of the ulcer and the granulations at the base. There could now be seen a central area of parietal bone occupying the base of the ulcer, and around that the tissue was apparently healthy. That greatly improved condition had persisted for a year and seven months. In treating bone cases Dr. Cumberbatch insisted on great care being taken not to allow the diathermy to damage the periostenm. - Dr. W. J. TURRELL, in discussing the treatment, said that no attempt should be made to treat the whole growth at once, when the wound was a large one, but that treatment should be proceeded with in stages, so that the effect of the previous application could be assessed before entering upon another.

Dr. H. A. ECcles showed, by means of the epidiascope, a valuable series of skiagrams of Fractured Jaws, from a

1 Final Report of Royal Commission on Tuberculosis, Part II Appendix Report on Tuberculin Tests. 